\title{
Synthesis of a Thienothiophene Conjugated Polymer
}

\author{
Alejandra S. Diez ${ }^{1}$, Silvana Saidman ${ }^{2}$ and Raúl O. Garay ${ }^{1}$ \\ ${ }^{1}$ INIQO, Universidad Nacional del Sur, Avenida Alem 1253, 8000 Bahía Blanca, Argentina \\ ${ }^{2}$ INIEC, Universidad Nacional del Sur, Avenida Alem 1253, 8000 Bahía Blanca, Argentina \\ Tel/Fax: +54 (291)-459-5187, E-mail: rgaray@criba.edu.ar
}

\begin{abstract}
A new conducting polymer was prepared by chemical and electrochemical polymerization of 3,6-dimethylthieno[3,2-b]thiophene. The galvanostatic deposition afforded uniform, adherent and dark blue films of PDMTT. Electrochemical characterization by cyclic voltammetry showed that it can be repeatedly driven between the doped and undoped species with a coulombic efficiency of nearly $100 \%$.
\end{abstract}

Keywords: conjugated polymers, electropolymerization, thienothiophene.

\section{Introduction}

Synthetic precursors (syntons) that contain thiophene units have originated series of polymers whose properties are being studied intensely [1]. For example, a significant increase of the non linear optical activity (NLO) in poly(arylenevinylene)s has been obtained by replacement of phenylene units by thiophene ones [2]. This result could be interpreted as an indication of the d-orbitals contribution to the NLO activity. It would be expected, therefore, that a further increase on the content of the highly polarizable sulfur atom in the backbone of the polymer will led to even higher values of the nonlinear electro-optical coefficients. Likewise, redox activity will be also changed by means of this structural change. We report here the chemical and electrochemical synthesis of poly(3,6-dimethylthieno[3,2b]thiophene), PDMTT, that represents a synthetically viable system in which these concepts could be examined.

\section{Experimental}

Monomer I can be obtained in the gram-scale in one-step reaction. The monomer was characterized by GC, ${ }^{1} \mathrm{H}-\mathrm{NMR},{ }^{13} \mathrm{C}-\mathrm{NMR}$ y MS. This reaction offer the possibility to obtain a highly symmetric derivative of thieno[3,2-b]thiophene whose regiochemistry is easier to control than the non-substituted parent compound. PDMTT was prepared as shown in Scheme 1 either chemically using $\mathrm{FeCl}_{3} / \mathrm{CHCl}_{3}$ or electrochemically from a solution $10^{-3} \mathrm{M}$ of $\mathbf{I}$ in acetonitrile with $\mathrm{LiClO}_{4}$. The potential cyclic polymerization was performed either on a vitreous carbon or on a platinum electrode in the potential 
range of $0.5 \mathrm{~V}$ and $1.5 \mathrm{~V}$. In addition, I was also galvanostatically electropolymerizated at current densities between 0.05 and $0.5 \mathrm{~mA} / \mathrm{cm}^{2}$.

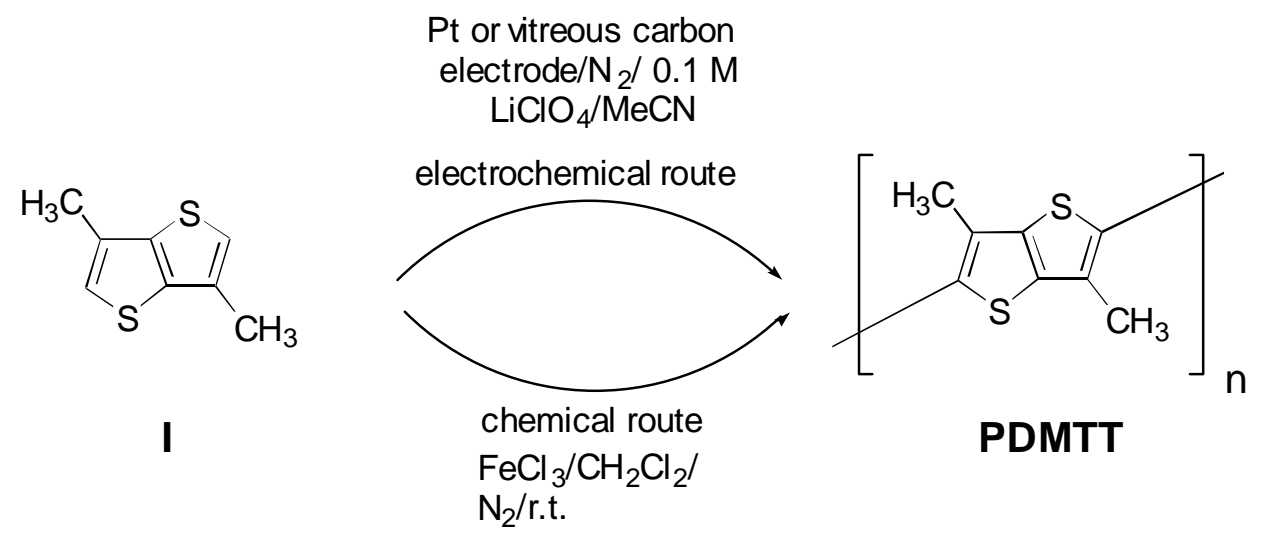

Scheme 1.

\section{Results and Discussion}

The chemical synthesis of PDMTT yielded a solid whose characterization is being carried on. On the other hand, this polymer was prepared by electropolymerization as a film supported by the electrode. However, in cyclic potential conditions it was not possible to obtain a self-standing film since the homogeneous growth at longer electropolymerization times only afforded a film of pulverulent nature with poor mechanic properties and low density. However, the galvanostatic deposition at density current of $0.1 \mathrm{~mA} / \mathrm{cm}^{2}$ afforded uniform and adherent films. The electrochemical characterization by cyclic voltammetry showed that the polymer can be repeatedly interchanged between the doped and undoped species with a coulombic efficiency of nearly $100 \%$ during four hours without degradation signs.

Acknowledgments: Financial support for this research was provided by ANPCyT and SGCyT-UNS.

\section{References and Notes}

1. Kraft, A.; Grimsdale, A. C.; Holmes, A. B. Electroluminescent conjugated polymers-Seeing polymers in a new light. Angew. Chem. Intern. Ed. 1998, 37, 402.

2. Nalwa, H. S. Organic Materials for Third-Order Nonlinear Optics. In Nonlinear Optics of Organic Molecules and Polymers; Nalwa, H. S.; Miyata, S., Eds.; CRC Press, 1997; Chapter 11, p 687.

3. Choi, K. S.; Sawada, K.; Dong, H.; Hoshino, M.; Nakayama, J. A one-pot synthesis of substituted thieno[3,2-b]thiophenes. Heterocycles 1994, 38, 143-149. 